\title{
Designed for Repair-ability: Learning from the German Country Schools of Gillespie County, Texas
}

\author{
BEN K. SHACKLETTE \\ Texas Tech University
}

If an act of repair to a building is necessitated by the ethical imperatives determined by a set of standards, what can be learned from the act itself, and from the standards, values, and intentions of vernacular builders who first create their buildings, and then over time discover the techniques and skills required to sustain those buildings through acts of maintenance and repair? This study focuses on the 19th and early 20th Century German vernacular rural schools of Gillespie County Texas which combine several types of structures, materials, and functional solutions representative of a system of cultural meaning and social behavior akin to the Texas German community. Beginning as one-room school houses, the rural school sites developed into community centers which are architecturally unique to that county, and not found elsewhere in Texas. No longer in use as schools, community engaged efforts have insured the survival and continued use of some of the school locations. Selected case studies are presented to illustrate the distinctive "self-build/self-repair" ethos practiced by the Germans of Gillespie County, a practice that has largely disappeared in the age of modern mass consumerism, and the examples may provide a model for communities seeking to preserve culturally significant buildings through community-based heritage outreach initiatives.

\section{THE HISTORY AND CULTURAL DEVELOPMENT OF THE GERMAN COUNTRY SCHOOLS}

The first Non-Native Americans to settle in Gillespie County, located in the west central area of Texas, were German immigrants who belonged to an organized immigration society sponsored by German noblemen. Arriving in 1846 and establishing the town of Fredericksburg, the German colonist were intent on maintaining strong economic and cultural ties to their German homelands, and they established an independent German colony separate and apart from other cultural influences. "Social and economic improvement, along with political idealism, were the primary goals of these Texas settlers." They were also deeply committed to preserving their traditions and language, and they immediately set up small schools in homes and churches in the very early stages of settlement. "A sense of community and social responsibility was very important to the Germans of Gillespie County, who placed great emphasis on the traditional values of church and school." Ranching and grazing became the main source of income for many families, and numerous small rural communities sprang up throughout the county resulting in "one-room" schoolhouses, often American Style log cabins, and in a few cases adobes copied from their Mexican neighbors. The modest means of the early settlers necessitated an expedient and affordable means of building for all types of structures, and this approach carried forward in the construction of country schools. In 1854, the State of Texas passed legislation which laid the foundation for a public education system comprised of "common school" districts through a voucher system partially funded by state money and supplemented with local revenues. To qualify for government funds, each county created districts managed by local trustees who were responsible for hiring teachers, providing books and desks, purchasing the land, building the schoolhouse, and providing the necessary maintenance and repair for each schoolhouse and the additional structures at each rural site. The German speaking communities in the Texas Hill Country were at the forefront of public education on the Texas frontier. "In Central Texas, however, counties with predominantly German populations were successful in starting commons schools. The Germans who emigrated to Central Texas in the 1840 s had come with the enlightened and progressive ideals of 19th century Europe and were adamant in their desire for free public schools." Through community volunteerism, a shared ethos of self-reliance, and a strong commitment to early education, the German "public free schools" became some of the best in the state, renown for administrative efficiency, adequate funding, and the building and maintenance of their locally owned schools.

Beginning with six "common districts" in 1854, the country schools of Gillespie County struggled through the Civil War years, survived the Northern Radical government during Reconstruction, and flourished from the 1880s through the 1920s reaching a peak of over 44 school districts by 1900 . The passage of the Gilmer Aikin Law in 1949, which consolidated the locally structured "common" public-school systems throughout Texas into state administered units, wrested ownership and control of the rural schools from the local communities, and by 1960, all the original German common country schools were closed. "As a result of the district mergers, countless rural schools-houses became obsolete in short order, and without a systematic plan for their continued use, many of them disappeared from the cultural landscape." After the "consolidation", many of the former common school buildings throughout Gillespie County remained active community centers for social clubs, family gatherings, polling places, and community events as they had prior to the closings. No longer receiving public money, some school buildings 


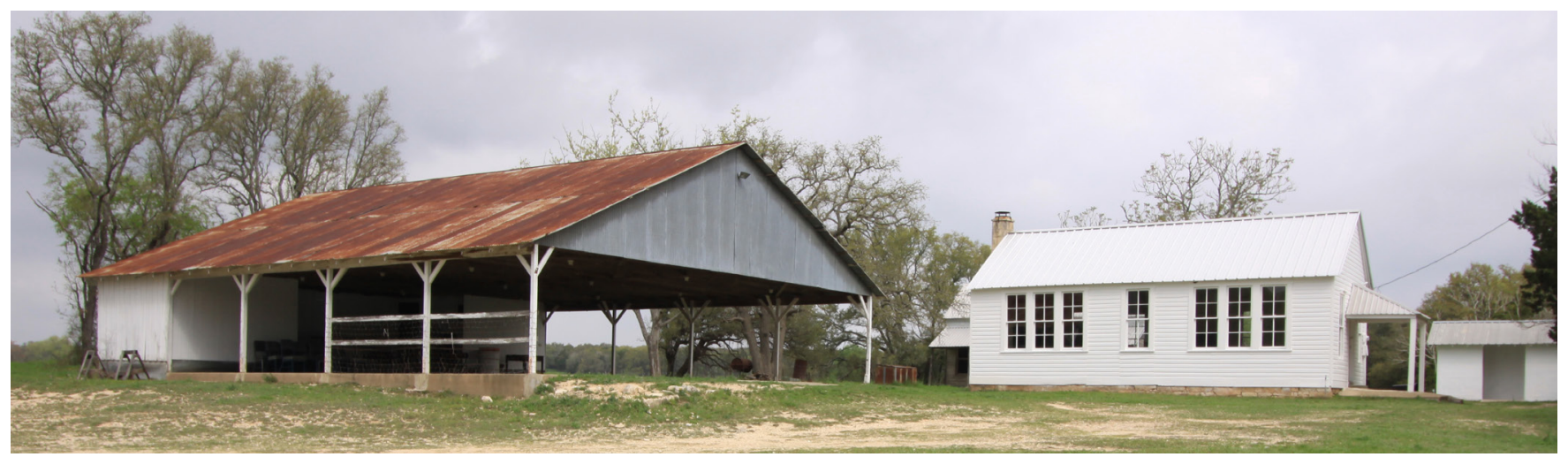

Figure 1: Rheingold School Pavilion \& Schoolhouse (Shacklette, 2016)

survived intact for the next fifty years because of the continued care and repair provided by the extended family groups who shared a strong bond of kinship associated with the historical significance of each small school. In 1999, citizens became concerned that the school buildings would be lost if the school system sold the land upon which twelve historic schools stood to private buyers. Working with legislators, the newly formed Friends of the Gillespie County Country Schools instigated the signing of Texas Senate Bill 116 which changed state laws allowing school properties to be donated to governmental or non-profit organizations at no cost. Today, the Friends oversee 12 historic German country school sites which are heritage destinations, available for public gatherings, and used for private meeting places accessible on the Gillespie County Country Schools Trail. The following section examines the ethical imperatives underlying the concern for repair and maintenance of each school where "ethical" refers to standards of conduct, "imperative" is defined as an unavoidable obligation or a necessary action, and the term "repair-ability" not only means an aptitude for fixing or patching, but the capacity to renew to a sound and healthy state.

\section{REPAIRABLE FEATURES OF THE GILLESPIE COUNTY COUNTRY SCHOOLS: RHEINGOLD SCHOOL}

The Rheingold community was established in 1859 on North Grape Creek northeast of Fredericksburg, and it is representative of the innovative local conventions or typologies in country school design and construction developed by the Germans during the late 19th and early 20th century. The first school building (Figure 2 No.5) was a 12' x 14' log cabin built in 1873 and it is typical of early German buildings in the mid-19th century. The original log cabin school was stuccoed on the south side and sided over with vertical wood boards at the gabled ends. It is mistakenly thought that covering the log cabin was an attempt to hide a crude type of building necessitated by the hardscrabble conditions of the early years of settlement. In fact, the Germans of the Texas Hill Country were critical of the traditional southern lob cabin, which required constant repair and were not very comfortable, and they raised the level of livability and reliability of the log cabin by infilling the spaces between the logs with brick and mortar instead of mud, and they routinely stuccoed their log cabins. These are exclusively Texas German innovations developed for both aesthetic and practical reasons. (See Figure 3) The $22^{\prime} \times 40^{\prime}$ wood frame schoolhouse existing today (See Figure 1 , right side) was constructed in 1900 using milled wood siding, which was easier to transport and faster to erect on site, and it allowed for larger glazed window openings not practical in either log or stone construction, which increased the amount of natural daylight to the interior rooms in the era before electricity became available. The original $1873 \mathrm{log}$ cabin was converted to the "teacherage", a permanent residence of the teachers who were hired by the school trustees.

The teacherage better accommodated a married teacher with a family, eliminated travel to the school location each day, and afforded the teacher in residence the opportunity to regularly maintain the buildings and the grounds. The log cabin teacherage was enlarged with a matching wood frame addition in 1881 extending to the west and doubling the size of the original cabin. A second addition of limestone, estimated to be from the 1920s, and measuring ten feet wide, was added to the north running the full length of the first two structures. (See Figure 2 No. 5) In the case of the teacherage, the Rheingold school trustees were prone to try different construction types in what appears to be an experimental process of trial and error. Log cabin to wood frame to Texas limestone is a progression that may indicate incremental changes in materials based on economy, determined by the skills of the volunteer builders, or a preference for more lasting materials. Limestone is considered a better material for building than exposed wood. The seemingly idiosyncratic choice of materials may also be linked to the development of roads in the county. In the earliest of times, the log cabin was the fastest way to construct a shelter. The logs were felled at or near the site and could be drug by horse to the building location. Early roads into the county would have made the transport of locally milled light wood framing by wagon more likely, and by the 1920 s roads had improved to the point where shipments of heavy stone from a nearby quarry would have been feasible. Another factor may be the preferred methods of construction available to the school trustees. 


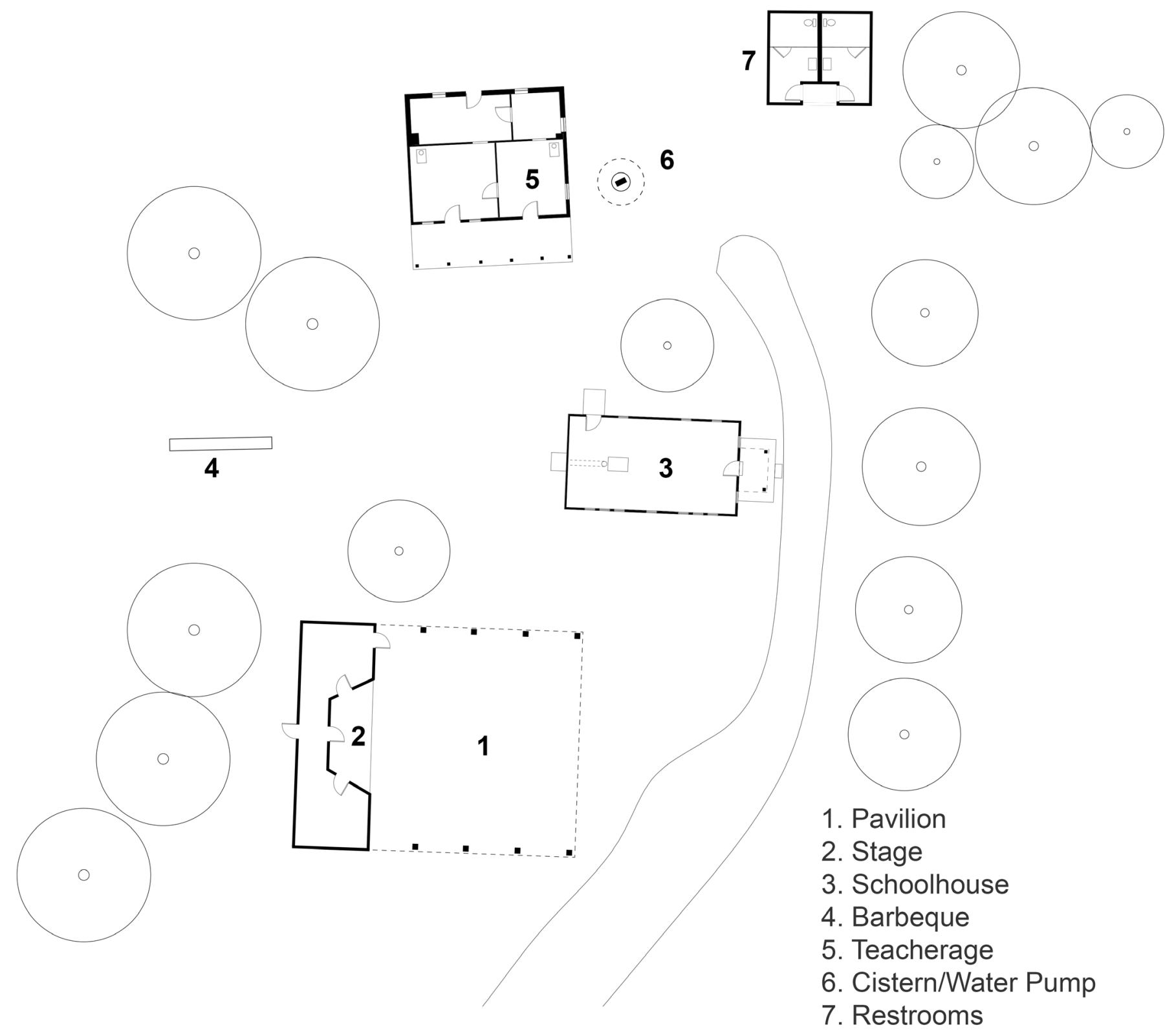

SITE PLAN: RHEINGOLD SCHOOL 334 Rheingold School Road

(4) $\begin{array}{ccc}0^{\prime} 5^{\prime} & 10^{\prime} \quad 25^{\prime} & 50^{\prime}\end{array}$ 


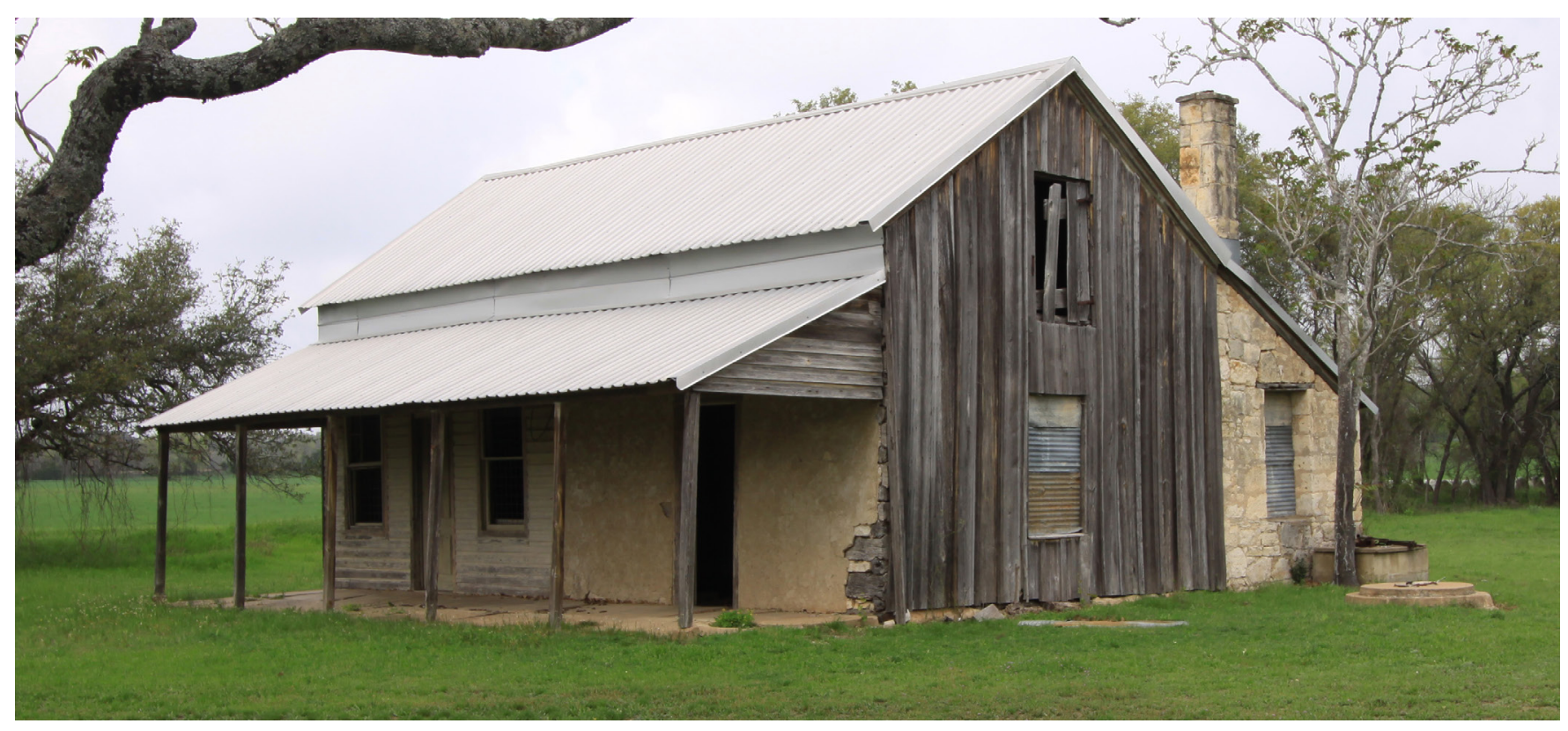

Figure 3: Rheingold School Teacherage South-East View (Shacklette, 2016)

Both donated and purchased materials and labor were used at various schools.

A unique building type developed at many of the German country school compounds is called the "pavilion". (See Figure 2 No.1 \& No. 2) These originated in the 19th Century as temporary covered gathering areas built as large open air "pole structures" and were at first covered with tree limbs and foliage. In the early 20th Century, permanent wood framed structures with shingle and tin roofs were constructed. Likely inspired by the open-air revival camp "tabernacles" common throughout the rural areas of the United States originating in the years following the Second Great Awakening, tabernacle construction methods introduced to the Texas Hill Country by settlers from Arkansas, Georgia, and Tennessee, would have been discoverable by the Germans of Gillespie County as many were constructed in nearby counties including McCulloch, Mills, and San Saba. Permanently constructed wood framed pavilions with enclosed walls featuring large operable hopper style windows, copied directly from the German society meeting halls and dance halls began to appear in the early 1930s at various school complexes in Gillespie County. At Rheingold, the pavilion is open-air with an enclosed stage area at the far gable end (See left side of Figure 1), "The school building, teacherage, and a later pavilion, were all built with materials and labor donated by the families of the community." Between 1917 and 1918 there was a violent anti-German movement across Texas which drove many communities to retreat inward, and during the years of Prohibition, the Germans of Gillespie County were ostracized for not supporting dry legislation as they continued to brew and consume beer in private. The remote country schools provided a safe and discreet gathering location for community events, and sophisticated pavilions were constructed at many of the schools after the repeal of the Volstead Act in 1933. The existing pavilion at Rheingold was "started in 1936 and finished in 1938 with materials and labor donated by the community." Each rural school held a traditional and elaborate end of the year celebration known throughout the county as the "School Closing", and admission fees from games, plays and dances, and the sale of German beer and barbeque supplemented the yearly expense of school maintenance and operations not covered by the state. The needed funds not raised at the closing were donated by the parents, and in-kind building materials and labor commitments constituted a significant portion of those donations.

The Rheingold school represents a wide range of building technologies used by the various school trustees and community members during the common school era. Controversy recently erupted within the community regarding the replacement of the aged red oxidized metal roofs on both the schoolhouse and teacherage when the decision was made to replace them with modern galvanized aluminum which has a longer life-span. Practical maintenance costs and material durability won over historically accurate aesthetics. Openness to innovation and modern trends in methods and materials has contributed to longer life spans for many of the buildings, whereas the tendency to rely on older and less durable approaches would have been less effective. Continued traditions in repair and upkeep of the schools does not always preclude the continued use of traditional materials.

\section{WILLIAMS CREEK SCHOOL}

Williams Creek School is southeast of Fredericksburg, and the school complex was built between 1897 and 1950. The original 1897 rectangular limestone schoolhouse (See right side of Figure 4) measuring $43^{\prime}$ by $23^{\prime}$ stood alone until 1923 when the $31^{\prime} \times 23^{\prime}$ metal clad wood frame addition, connected by a semi-enclosed dogtrot, was extended to the west. (See 


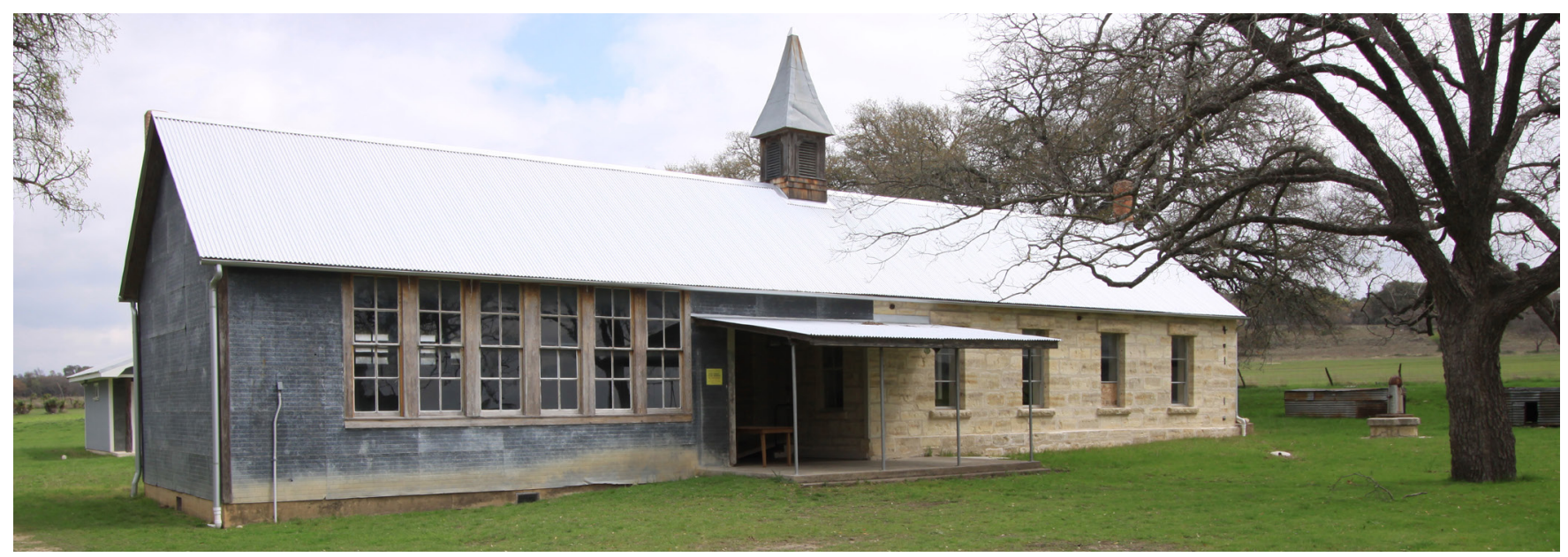

Figure 4: Williams Creek School/Community Center. (Shacklette, 2017)

left side of Figure 4) Providing an intact view of rural education in Gillespie County in the late nineteenth and early twentieth century, the building has remained unchanged and in continuous use for over one-hundred years. The original roof has been regularly repaired and recently replaced with galvanized metal. The windows are original on the west wing, and in 1950, the wood windows on the limestone wing were replaced with aluminum units. The masonry has been regularly cleaned and repointed, an extensive undertaking, and the classrooms are maintained with authentic desks to appear as they were a century ago. The pine tongue and groove floor and the beaded board ceilings are original.

\section{LOWER SOUTH GRAPE CREEK SCHOOL}

Located east of Fredericksburg, Lower South Grape Creek School was built between 1901 and 1956, and served as the primary social center to the dispersed community who lived along the lower banks of South Grape Creek. Originally located elsewhere, classes were moved to the original 1901 rectangular stuccoed limestone schoolhouse which is covered with a metal-clad roof. (See right side of Figure 5) The wood framed metal clad addition (See left side of Figure 5) was added in 1936 as an open-air porch. As customary at other schools, a well house, barbeque pit, restrooms, playground equipment, and a barn or garage were constructed on the site in the 1940s. The v-crimp metal roof and the interior stone chimney on the west end of the limestone building are thought to be original. The exterior and interior walls of the 1901 limestone schoolhouse were plastered in the 1930s, and the porch was enclosed with wood framing and embossed metal siding around 1956 . The metal has been painted white to match the plastered limestone walls, and the bell tower, thought to have been added after 1920, is constructed using horizontal wood lap siding.

\section{LEARNING FROM THE PAST}

The German tradition of compulsory education, an ethical imperative brought from the homeland to Texas, was maintained in a primitive setting by creating a self-styled system for rural education that was from 1854 to 1949 largely independent from external governmental, religious, and cultural influences. The builders of the German Schools of Gillespie County worked from a set of shared values, they developed a local expertise in natural building materials such as stone, log, and milled wood, and they merged these natural materials with tested manufactured products used by local craftsmen and purchased from regional mercantile outlets. Clearly, the case can be made that knowing how to build a certain thing is pertinent to knowing how to repair that same thing, and having to repair the thing informs decisions in building new things. If something broke or needed to be replaced it could be easily made or bought. They learned from their non-German speaking neighbors by observing, borrowing, and interpreting methods, stylistic elements, and material uses, and yet they developed and maintained a commonly understood technical and aesthetic tradition. The Germans in Gillespie County created a distinctive architecture that can be experienced as a visual narrative constructed using linguistically appropriate and familiar rules that like "the spoken word can be learned and practiced." Over time, the schools have evolved in response to changing internal and external social conditions, but their purpose as valuable community capital has not waivered. They are a vernacular building typology built in an architectural "language or dialect naturally spoken by the people of a particular country or district." The modest means of the rural settlers necessitated an expedient means of building repair suited to remote locations. The lack of adornment and the rugged minimalism expressed in the typical school facade drew on commonly understood knowledge learned from other rural German buildings in the region. The common school era required each county district, without state help, to construct and maintain the actual school buildings and this deeply embedded "self-build/self-repair" ethos practiced by the Germans of Gillespie County insured the long-term repair-ability of the schools, particularly in the years following the school closings. 


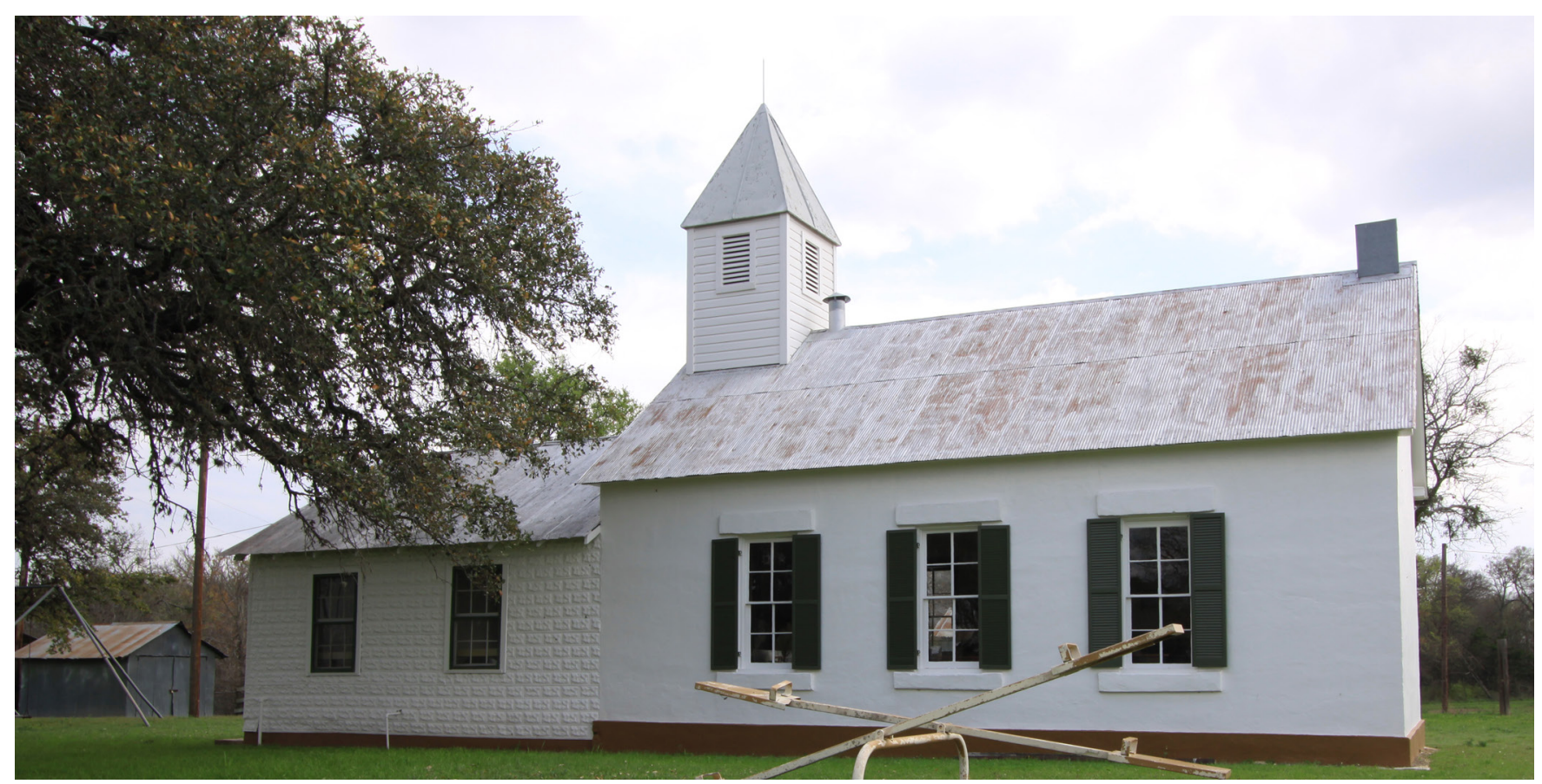

Figure 5: Lower South Grape Creek Schoolhouse/Community Center (Shacklette, 2016)

\section{LIVING IN THE PRESENT}

The Crabapple School, one of the twelve school/community centers on the Gillespie County Country Schools Trail, dates to 1882 when the current limestone schoolhouse was erected. Today, it is a fully functional and regularly used community center with an enclosed wooden pavilion, and a free-standing stone teacherage. An active country school and regional social center for seventy-five years, the school officially closed in 1957 under the state consolidation mandate. It has remained in continuous use since the closing accommodating a range of community activities for the last sixty years. The limestone school house was constructed in 1882 for $\$ 600$ in materials with mostly donated labor provided by the parents of the students, which is equivalent to about $\$ 13,700$ in 2018, a remarkable rate of return for a structure that has remained in continual use for one hundred and thirty-six years, even when considering periodic maintenance and routine upkeep. Today, it is unlikely that most Americans can participate in the making and repairing of their built environments in the same way extended rural families did in the 19th century when the seasonal rhythms of agricultural life afforded flexible spaces of time for communal building projects. Many of the ongoing country school maintenance and repair projects today involve volunteers from the rural agricultural community who do not have to take a vacation day to put on a new roof or replace a window, and when needed, professional services are also contracted, or in some cases, donated. The modest rural one-room school incrementally evolved into useful multifunctional centers for community celebrations and social interaction which continued to benefit the communities after the closing of the schools. Designed to be smaller in scale and less technologically complex than contemporary buildings make them easily repair-able, and because they exist outside the strict codes and regulations of municipalities, it is economically feasible to keep them in good condition for regular use. Each school has a board of officers and members who exemplify the impact participatory building events can contribute to social cohesion and a heightened sense of community well-being. "After participating in design, people claim a share in its success and are reminded of it daily for years. People grow to feel at one with the community when its architecture reflects their shared values. Participation in design counters alienation." The schools remained useful and important after closing as public schools in the 1950s because of volunteerism on the part of the descendants of the school students who valued the utility of the structures, and held deep consanguineous attachments to the buildings which has been forged over several generations. Jo Ella Sifford Lewis, an active rural school supporter who attended the school at Wrede said the dedication to maintain the schools after the closings stemmed in part from the hard times of the Great Depression. It was ethically, or in her words "morally wrong to spend the time and money to build something and then just let it go to waste." The schools show how knowledge about and the motive for building and repairing are ethical imperatives which are socially transmittable from one generation to the next. The how and the why to repair is critical cultural information necessary for the continued repair and maintenance of the rural schools.

Fredericksburg and Gillespie County is one of the most exclusive communities in Texas today with huge financial investments pouring in from the outside world. Winemaking, tourism, retail, and high-end retirement relocation has put pressure on the local community creating both positive 
and negative results. The rural schools are timepieces of material culture that have, so far, been immune to the commodification and appropriation of the Texas German cultural landscape that has affected the more urban areas of the region. The rural schools, which are not for sale, are physically accessible to the public, promoted as heritage tourism sites, and continue to be regular meeting places for clubs, families, and local organizations. When asked about the future of the country schools Helen Birck, a school supporter who attended Crabapple and Cherry Spring Schools from 1955-1964, said "When we are no longer able to function as a club we worry." As family lines die out and descendants move away, the future of the schools may be in question. The deep relationship between the schools and their respective communities is not a notion that can be easily understood by auslanders (outsiders) who are growing in numbers as gentrification slowly displaces the once close knit and ethically cohesive community. James Kunstler observes that Modernism did immense damage "by divorcing the practice of building from history and the traditional meanings of building." If this is true regarding the rural schools, their survival as authentic cultural material depends on a new generation of descendants taking up the cause and learning the history and practical traditions in building and repair. Beyond Gillespie County, the schools demonstrate how other communities can benefit from a shift to an increased opportunity for a broader range of community participation in everyday building and building repair. In his book Shop Class as Soulcraft, Matthew Crawford questions the industrial age educational goal of creating "knowledge workers" who can separate thinking from doing as a way of enduring the assembly line. Crawford makes a compelling argument when he posits: "The current educational regime is based on a certain view about what kind of knowledge is important: "knowing that", as opposed to "knowing how". This corresponds roughly to universal knowledge versus the kind that comes from individual experience. Practical know-how, on the other hand, is always tied to the experience of a particular person." The repair of small scale buildings like the rural schools, which are constructed from "low tech" materials and systems, can be community service activities for young people and college students, particularly architecture students, providing an opportunity to reconnect society to the intrinsic satisfactions and cognitive challenges associated with the manual work of craft in building and building repair. Vernacular building repair as organized educational events aimed at saving buildings through practical "hands-on" experience.

Henry Glassie asserts that the authentic vernacular tradition "is based on participation, engagement, and an egalitarian political ethic" His definition accurately describes the communal acts of building, improving, and repairing developed by the German rural school communities in the 19th Century, and still practiced today as an integral component of their built heritage preservation strategy. Glassie goes on to say "much of the connection to these forces has been lost in modern society, and this has led to ignorance, weakening of culture, and a decline in personal empowerment. By way of contrast, the plain form of the vernacular building represents the external image of an enduring social idea." Purists who insist on historically accurate restorations will likely find fault with the local methods and materials used by the community. The buildings are very much alive and not aesthetically frozen in another time. The attention to maintaining adequate roofs, the replacement of windows and doors, stabilization to foundations, and the regular painting and sealing of exterior finishes, all of which contribute significantly to the survival of the schools, is performed using everyday modern technology. The "plain form" of the rural German schools deserves little attention as significant accomplishments in academically inspired architectural design. They are modest, utilitarian, durable, and very repair-able. Where funding for expensive restorations projects is often scarce, the resourceful, inventive, and thoughtful approach implemented by the Texas Germans will provide the continued care the schools will need to remain sustainable historic places, and function as valuable community centers into the foreseeable future. Motivated by an "enduring social idea", the Gillespie County Texas German community continues a traditional commitment to maintain the rural schools in a sound and healthy state, and this causes them to be worthy of consideration.

\section{LOOKING TO THE FUTURE}

Fredericksburg and Gillespie County is one of the most exclusive communities in Texas today with huge financial investments pouring in from the outside world. Winemaking, tourism, retail, and high-end retirement relocation has put pressure on the local community creating both positive and negative results. The rural schools are timepieces of material culture that have, so far, been immune to the commodification and appropriation of the Texas German cultural landscape that has affected the more urban areas of the region. The rural schools, which are not for sale, are physically accessible to the public, promoted as heritage tourism sites, and continue to be regular meeting places for clubs, families, and local organizations. When asked about the future of the country schools Helen Birck, a school supporter who attended Crabapple and Cherry Spring Schools from 1955-1964, said "When we are no longer able to function as a club we worry." As family lines die out and descendants move away, the future of the schools may be in question. The deep relationship between the schools and their respective communities is not a notion that can be easily understood by auslanders (outsiders) who are growing in numbers as gentrification slowly displaces the once close knit and socially cohesive community. James Kunstler observes that Modernism did immense damage "by divorcing the practice of building from history and the traditional meanings of building." If this is true regarding the rural schools, their survival as authentic cultural material depends on a new generation of descendants taking up the cause 
and learning the history and practical traditions in building and repair. Beyond Gillespie County, the schools demonstrate how other communities can benefit from a shift to an increased opportunity for a broader range of community participation in everyday building and building repair. In his book Shop Class as Soulcraft, Matthew Crawford questions the industrial age educational goal of creating "knowledge workers" who can separate thinking from doing as a way of enduring the assembly line. Crawford makes a compelling argument when he posits: "The current educational regime is based on a certain view about what kind of knowledge is important: "knowing that", as opposed to "knowing how". This corresponds roughly to universal knowledge versus the kind that comes from individual experience. Practical knowhow, on the other hand, is always tied to the experience of a particular person." The repair of small scale buildings like the rural schools, which are constructed from "low tech" materials and systems, can be community service activities for young people and college students, particularly architecture students, providing an opportunity to reconnect society to the intrinsic satisfactions and cognitive challenges associated with the manual work of craft in building and building repair. Vernacular building repair as organized educational events aimed at saving buildings through practical "handson" experience.

Henry Glassie asserts that the authentic vernacular tradition "is based on participation, engagement, and an egalitarian political ethic" His definition accurately describes the communal process of building, improving, and repairing developed by the German rural school communities in the 19th Century, and still practiced today as an integral component of their built heritage preservation strategy. Glassie goes on to say "much of the connection to these forces has been lost in modern society, and this has led to ignorance, weakening of culture, and a decline in personal empowerment. By way of contrast, the plain form of the vernacular building represents the external image of an enduring social idea." Purists who insist on historically accurate restorations will likely find fault with the local methods and materials used by the community. The buildings are very much alive and not aesthetically frozen in another time. The attention to maintaining adequate roofs, the replacement of windows and doors, stabilization to foundations, and the regular painting and sealing of exterior finishes, all of which contribute significantly to the survival of the schools, is performed using everyday modern technology. The "plain form" of the rural German schools deserves little attention as significant accomplishments in academically inspired architectural design. They are modest, utilitarian, durable, and very repair-able. Where funding for expensive restorations projects is often scarce, the resourceful, inventive, and thoughtful approach implemented by the Texas Germans will provide the continued care the schools will need to remain sustainable historic places, and function as valuable community centers into the foreseeable future. Motivated by an "enduring social idea", the Gillespie County Texas German community continues a traditional commitment to maintain the rural schools in a sound and healthy state, and this causes them to be worthy of consideration.

\section{ENDNOTES}

1 Lich, Glen E. The German Texans, (San Antonio, Texas: The University of Texas Institute of Cultures at San Antonio, 1981), 16.

2 Kohout, Martin \& Donell, Gillespie County (Handbook of Texas Online), accessed January 14, 2017, https://www.tshaonline.org/ handbook/online/articles/hcg04

3 Fisher, Alice \& James D., Common Schools of Texas: Past and Present, (Austin, Texas: Heritage, Volume 4, Number 2, Texas Historical Foundation, 1986), 23.

4 Utley, Dan \& Beaman, Cynthia J., History Along the Way (College Station, Texas: Texas A\&M University Press, 2013), 117

5 Pue, Ronni, On the Trail: Historic County Schools Spotlighted on New Drive Starting Saturday, (Fredericksburg, Texas: Fredericksburg Standard-Radio Post, March 26, 2006) Section D, 8

6 Shacklette, Ben, An Interview with Ruben Warhmund, A Former Student at Rheingold School, (Fredericksburg, Texas: Recorded December 30, 2016)

7 Dovey, Kim. "The Silent Complicity of Architecture" (Burlington, Vermont: Habitus: A Sense of Place, Edited by Jean Hilliard and Emma Rooksby, Ashgate Publishing Limited, 2012),300.

8 Hooker, Van Dorn, "Vernacular Architecture", (Albuquerque, New Mexico: New Mexico Architecture, Sept.-Dec. Edition, 1990),7

9 King, Stanley, Co-Design: A Process of Design Participation, (New York, New York: Van Nostrand Reinhold, 1989) 3.

10 Shacklette, Ben Recorded Interview with Helen Birck, Eileen Izard, Sylvia Izard, James Feuge, and Jo Ella Sifford Lewis, (Fredericksburg, Texas: December 29, 2016)

11 Ibid.

12 James Howard Kunstler, The Geography of Nowhere the Rise and Decline of America's Man-made Landscape (New York, New York: Touchstone Simon and Schuster, 1993), 59.

13 Crawford, Matthew. Shop Class as Soul Craft: An Inquiry into the Value of Work, (New York, New York: Penguin Press HC, 2009), 162.

14 Glassie, Henry, "Architects, Vernacular Traditions and Society", (Berkeley, California: Traditional Dwellings and Settlements Review, IASTE, Vol.1, 1990),9. 